\title{
OUTCOME OF INSULINOMAS DIAGNOSED IN A TERTIARY ENDOCRINE CENTER
}

\section{R.A. Trifanescu ${ }^{1,2, *}$, I. Baciu ${ }^{1,2}$, M. Gheorghiu1,2, A. Dumitrascu², C. Poiana ${ }^{1,2}$ \\ ${ }^{1}$ Dept. of Endocrinology, "Carol Davila” University of Medicine and Pharmacy, 2 "C.I. Parhon" National Institute of Endocrinology, Bucharest, Romania}

BACKGROUND: Insulinomas, the most common functional neuroendocrine tumours of the pancreas, are usually sporadic, benign and solitary.

AIMS: To assess biochemical data, localization and treatment outcome of insulinomas diagnosed in a tertiary endocrine center.

\section{PATIENTS and METHODS:}

$>25$ patients $(14 \mathrm{~F} / 11 \mathrm{M})$, aged $49.1 \pm 14.1$ years, diagnosed with insulinoma between $2000-2014$ were retrospectively reviewed. Average body mass index $=30.4 \pm 7.5 \mathrm{~kg} / \mathrm{m}^{2}$.

$>$ 72-hour supervised fast was used for diagnosis of insulinoma (plasma glucose $<40 \mathrm{mg} / \mathrm{dL}$ with simultaneous insulin level $>6 \mu \mathrm{lU} / \mathrm{mL}$ ).

$>$ computed tomography (CT), magnetic resonance imaging, endoscopic ultrasonography and intra-operative ultrasonography were performed for tumour localization.

RESULTS: Median duration of hyperinsulinemia $=2$ years;

Sporadic insulinomas : 23 patients (92\%); MEN 1 syndrome: 2 patients $(8 \%)$;

Hepatic metastases: 2 patients $(8 \%)$.

Table 1. Biochemical and hormonal data during 72-hour fast

\begin{tabular}{|c|c|c|}
\hline & Value & Percentiles $\left(25^{\text {th }} ; 75^{\text {th }}\right)$ \\
\hline Median duration (hours) to nadir glucose & 8 & $4.25 ; 12.25$ \\
\hline Glucose nadir (mg/dL) & $30.9 \pm 7.1$ & $26.8 ; 36.2$ \\
\hline Median insulinemia $(\mu \mathrm{IU} / \mathrm{mL})$ during nadir glucose & 28 & $15.2 ; 67.2$ \\
\hline Mean C peptide $(\mathrm{ng} / \mathrm{mL})$ during nadir glucose & $2.6 \pm 1.8$ & $1.9 ; 3.5$ \\
\hline
\end{tabular}

Figure 1. Preoperative localization of insulinoma

Figure 2. Therapeutic outcome ( $n=21$ out of 25)

$\begin{array}{ll}\text { Cephalic } & \text { Uncinate process } \square \text { Pancreatic neck } \\ \text { Pancreatic body } & \text { Pancreatic tail }\end{array}$

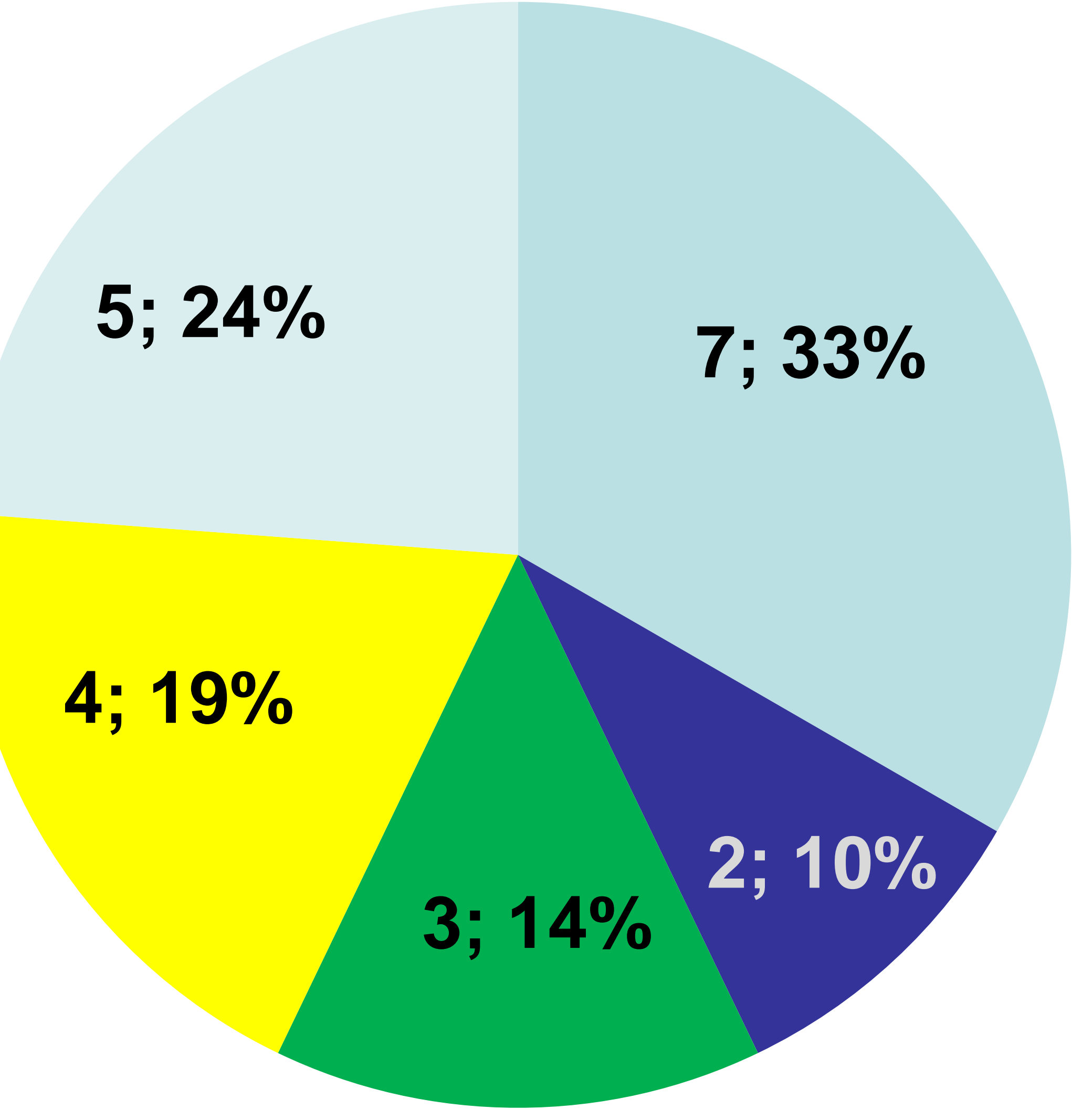

Mean tumour diameters: $22.3 \pm 14.3 \mathrm{~mm}$

Intraoperative ultrasound localization was necessary in 4 cases.
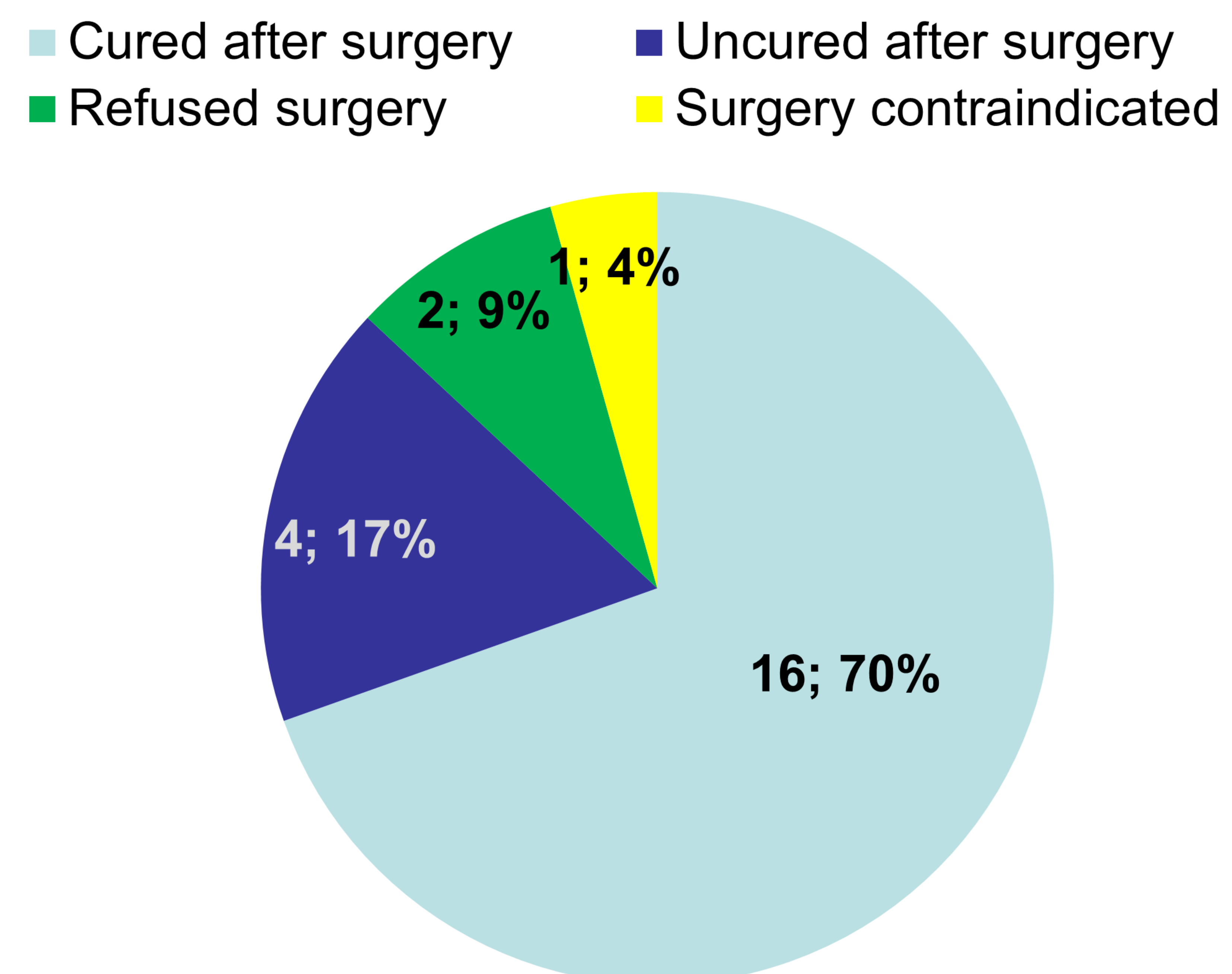

Surgery: enucleation / cephalic duodenopancreatectomy /distal pancreatectomy);

Medical treatment (diazoxide $200-300 \mathrm{mg} /$ day or somatostatin analogues) were used in non-cured patients to control hypoglycemia.

CONCLUSION: Partial pancreatectomy or enucleation provided a good cure rate in patients with pre-operative localized insulinomas. 